\title{
Numerical investigation into the failure of a micropile retaining wall
}

\author{
Pere C. Prat ${ }^{*}$ \\ Dept. of Civil and Environmental Engineering, UPC-BarcelonaTECH, Spain
}

\begin{abstract}
The paper presents a numerical investigation on the failure of a micropile wall that collapsed while excavating the adjacent ground. The main objectives are: to estimate the strength parameters of the ground; to perform a sensitivity analysis on the back slope height and to obtain the shape and position of the failure surface. Because of uncertainty of the original strength parameters, a simplified backanalysis using a range of cohesion/friction pairs has been used to estimate the most realistic strength parameters. The analysis shows that failure occurred because overestimation of strength and underestimation of loads.
\end{abstract}

Keywords: numerical analysis; FEM; ground failure; micropiles; retaining walls; back analysis

\section{Introduction}

A temporary micropile retaining wall with anchored tiebacks, which had been embedded in the ground before the excavation of an underground parking garage, collapsed after about $40 \%$ of the excavation had been completed [1]. The parking garage was a new addition to an old building that was being rehabilitated. Its construction required an excavation to an average depth of $16 \mathrm{~m}$ from the existing ground level, involving a total surface area of about $1400 \mathrm{~m}^{2}$. Because of limited space for the parking garage between the old building and an amusement park it was not possible to safely slope the excavation sides. For that reason, a temporary retaining wall was needed before the actual excavation of the ground. The procedure is sketched in Figure 1: first the temporary wall would be constructed embedded in the ground without much disturbance to the surroundings, then the excavation would start on one side of the wall and the tiebacks put in place. The excavation would continue by stages until reaching the required depth. This is a rather common technique for deep foundations of retaining systems which can be constructed using precast or cast-in-place diaphragm walls, bored piles or micropile systems of several types (secant, tangent, discontinuous). This

\footnotetext{
* Assoc. Prof. of Civil Engineering; Dept. of Civil and Environmental Engineering, School of Civil Engineering, UPC-BarcelonaTECH; Jordi Girona 1-3, 08034 Barcelona, Spain. Ph: +34 934016511; email: pere.prat@upc.edu
} 
technique first appeared in the 1950s [2] and has been developed and used in the past halfcentury not only for excavations but also for slope stabilization, ground improvement, underpinning of monuments, rehabilitation of historical structures, seismic retrofit, etc. [316]. The behaviour and failure of embedded or anchored in situ retaining walls has been extensively investigated as well in recent years [17-25]. A satisfactory performance of this type of structures requires sufficient knowledge of the geometric, topographic, hydrologic and geologic characteristics of the site, and of the material properties of the ground.

The original design of the case presented in this paper, specified a bored pile wall to stabilize the grounds of the adjacent amusement park. However, shortly before the construction began the design was changed to a micropile wall. This micropile wall eventually failed during the excavation.

After the failure, doubts were raised regarding several aspects of the construction process: ground characterization, design, construction issues and worthiness of the micropile/tiebacks system, effect of changing water conditions, etc. as possible causes of the failure.

Analysis of the construction logs and visual inspection of the site, especially the part of the wall that remained intact after failure, brought consensus between property, contractor and external consultants, that the construction of the micropile/tiebacks system had been properly executed according to design specifications. This was further justified with a in-situ load test performed by an independent contractor on a newly cast micropile of the same type used in the failed wall. This load test showed that the pile performed well within the strength parameters specified in the design.

Also in question was the true position of the water table at the moment of failure, since there was evidence from precipitation records and instrument readings in the area that the water table could be located near the surface after intense rainfall. However, records of rainfall accumulation during the days preceding the collapse show that rain episodes on those days were minimal. Seepage induced from leakage of a nearby water tank is considered irrelevant because the small volume of water involved could not significantly change the position of the water table. Therefore, it seems unlikely that the water table had moved to near-surface levels at the time of the wall's failure and, in any case, the micropile wall that had been constructed was in essence "discontinuous" and consequently completely permeable during this temporary construction stage. Water pressures on the wall would then be automatically cancelled. Similarly, seepage forces were unlikely to play a significant role if 
the water table was not near the surface. If that had been the case, the seepage regime would have been quite complex and further study would be needed. Finally, assuming that the water table did not change its position in the days preceding the failure, there could be no reduction of effective stresses and loss of shear strength because loss of suction [26-29] as the degree of saturation increases.

After ruling out poor construction techniques and water effects as direct causes of the failure, there remained ground characterization (both geotechnical parameters and topography), and design of the wall based on the information available about the site conditions as main suspects. These were the issues left to further investigate the causes of failure and establish proper responsibility. It was decided to perform a numerical analysis to simulate the failure process with the design ground topography and with the actual ground topography, to establish the most likely failure scenario and to determine the quality of the ground parameters used in the design.

The numerical analysis had to provide answers to the following: (a) whether the wall could fail with design strength and with design topography; (b) whether the wall could fail with design strength and with actual topography; (c) if the answer to the previous questions was negative, repeat the analysis with the actual topography and with a range of strength parameters of smaller values than the design ones, until failure was reached. The strength parameters for which failure is predicted are the most likely actual strength parameters of the ground. The numerical analysis also provides the shape and position of the failure surface.

It will be shown that the failure of the micropile wall can be attributed to a poor and incomplete knowledge of the ground's geotechnical properties and a lack of detail of the topographic data (see Figure 3 and Figure 4) which led to an overestimation of strength and an underestimation of the loads carried by the wall and tiebacks.

\section{Location and geological data}

The location where the failure occurred is a hill near Barcelona, Spain. It has an irregular rounded triangular shape (Figure 2), with a total surface area of approximately $6000 \mathrm{~m}^{2}$. The topography is determined by its location near the top of a hill which is at the SE end of the coastal range that runs approximately parallel to the coast and is formed by a sequence of low-height ranges. The lithology units outcropping in the range are the oldest in the area, consisting mainly of meta-sedimentary Palaeozoic rocks, especially dark slates, and hornfels 
and phyllites as a result of the contact metamorphism produced by the presence of a granitic batholith, currently outcropping at the foothills.

Within the plot limits the rock mass consists mainly of fractured slates of poor quality, with an RMR [30, 31] between 21 and 29. This rating would already suggest preliminary estimates of the strength parameters of about $c^{\prime} \approx 10-20 \mathrm{kPa}$ and $\varphi^{\prime} \approx 15^{\circ}-25^{\circ}$, much lower than those used in the original design. However, these values may be only crude approximations to the actual values. For instance, using Hoek \& Brown's failure criterion [32] the strength parameters are $c^{\prime} \approx 15 \mathrm{kPa}$ and $\varphi^{\prime} \approx 35^{\circ}$. These are still lower than the values used for the original design, but perhaps closer to the actual values, as will be shown in the following sections.

\section{Description of the failure}

Laboratory and field data were limited. For design purposes one sample was taken for laboratory testing. That sample, however, may not have been representative of the material near the failed wall because it had been taken from a considerable distance $(35 \mathrm{~m})$ from that zone. Based on that sole laboratory test, the geotechnical report gave the values of the strength parameters $c^{\prime} \approx 50 \mathrm{kPa}$ and $\varphi^{\prime} \approx 44^{\circ}$.

In the original design no topographic survey was conducted outside the property boundaries, assuming incorrectly that the ground surface extended horizontally into the amusement park (Figure 3 and Figure 5). Because of that, the lateral pressure on the micropile retaining wall was assumed to be caused only by the $5 \mathrm{~m}$ of earth surcharge left after excavating to the plane of the micropile heads. However, the actual topography outside the property boundaries, seen in a topographic survey conducted after the collapse (Figure 4), had an uphill back slope with an actual height of $10 \mathrm{~m}$, instead of the $5 \mathrm{~m}$ assumed in the original design.

The temporary micropile wall consisted of 10.5 m-long continuous steel pipes of 114.3 $\mathrm{mm}$ in diameter and $7 \mathrm{~mm}$ of wall thickness, filled with mortar without reinforcing bars, designed for shaft resistance only. The elastic limit of the pipes was approximately $550 \mathrm{MPa}$ and the yield strength approximately $600 \mathrm{MPa}$. Mortar strength was $20 \mathrm{MPa}$. Each micropile had a compressive strength of $1129 \mathrm{kN}$, and a bending strength of $28.4 \mathrm{kN} \times \mathrm{m}$. There were two micropiles per meter of wall, for a total bending strength of $56.8 \mathrm{kN} \times \mathrm{m} / \mathrm{m}$. To stiffen the wall, a reinforced concrete cap beam was constructed joining the heads of the micropiles at 
surface level. Figure 5 shows a typical cross-section used in the plane-strain analysis. Local datum is at elevation $+486.83 \mathrm{~m}$ a.s.1., two meters below the head of the micropiles. The initial ground level was located at elevation $+493.83 \mathrm{~m}$ a.s.1., from which $5 \mathrm{~m}$ were excavated to reach local reference $+2.00(+488.83 \mathrm{~m}$ a.s.1. $)$, head of the micropiles. After the micropiles and the cap beam were in place, excavation started from that level and when it reached level $+1.00(+487.83 \mathrm{~m}$ a.s.1.), the upper row of anchored tiebacks was installed. Failure occurred approximately when the excavation reached level -3.00 (+483.83 $\mathrm{m}$ a.s.1.), approximately $5 \mathrm{~m}$ below the cap beam.

Figure 6 shows a picture of the area where the excavation was being made and where the collapse occurred (at the right of the picture). Figure 7 shows a general view of the failure area. An intact portion of the wall with the cap beam can be seen on the left of the picture. The failed portion is at the right of the image where the new slope created by the sliding ground is clearly visible. Figure 8 shows a partial view of the failed zone where parts of the broken piles and cap beam can be seen scattered on the ground surface. The conditions of the zone immediately after the failure were not preserved intact after it occurred, because swift action was taken by the contractor to clean the area. Therefore, there was only limited graphic documentation. However, verbal description given by the personnel working in the construction site suggested that most of the tiebacks failed due to excessive tension, while some were pulled out with the wall as it moved laterally with a rotation and translation motion.

With this limited preliminary information, the most likely failure mechanism is illustrated in Figure 9, in which it is assumed, as suggested from a simple analysis using Blum's method [33], that when a plastic hinge develops in the micropile because the bending moment exceeds its bending strength, the load on the tieback is still less than its yield limit. Step (a) in this figure shows the initial condition in which the back slope surcharge acts as a load without contributing to the strength. With this conditions, when the bending moment on the micropile exceeds the yield moment, step (b), a plastic hinge forms, releasing the confinement of the earth behind the retaining wall so that the earth pressure is applied only to the less deformable elements: the tieback and the embedment. At this time the ground behind the wall has failed and has no apparent cohesion. The earth pressure is then transferred mostly to the tieback thus increasing its load until it reaches the yield limit of the steel cables, step (c). After that, failure of the tiebacks and of the micropile happens immediately, step (d), with the consequent collapse and sliding of the ground towards the existing excavation surface. 


\section{Numerical analysis}

The results of this work come from two numerical analyses. The first one has been carried with the commercial code PARATIE ${ }^{\text {TM }}$ [34], a FEM-based nonlinear computer code specific for flexible earth-support structures. The second analysis has been conducted with a generalpurpose FEM code, DRAC [35] that has been used to carry a nonlinear plane-strain analysis.

The main objectives of the numerical analyses have been: (a) determination, by means of a simplified backanalysis described later, of the most likely strength parameters of the ground; (b) evaluation of the influence of the height of the back slope on the lateral pressure on the micropile retaining wall; (c) determination of the most likely ground failure surface; and (d) to explain the reasons why the micropiles failed.

The numerical analysis was conducted using a Mohr-Coulomb constitutive model. Because of the uncertainty about the actual strength parameters, the analysis was conducted using several combinations of the strength parameters $\left(c^{\prime}, \varphi^{\prime}\right)$, each chosen in a range within reasonable upper and lower bounds. The objective was to determine the $\left(c^{\prime}, \varphi^{\prime}\right)$ pairs that would not lead to failure. This provides an estimate of the boundary in the $c^{\prime}-\varphi^{\prime}$ space (see Figure 10) between the values of strength that lead to failure and those that do not, thus giving an estimate range of the actual strength properties of the ground that have to be on this boundary, since it is known that the wall did fail. The strength parameters used in the design of the micropile wall $\left(c^{\prime} \approx 50 \mathrm{kPa}\right.$ and $\left.\varphi^{\prime} \approx 44^{\circ}\right)$ were obviously overestimated and therefore the actual strength parameters had to be less than those values. The lower bounds have been fixed at $c^{\prime}=0 \mathrm{kPa}$ and $\varphi^{\prime}=20^{\circ}$. In total, $36\left(c^{\prime}, \varphi^{\prime}\right)$ pairs have been used (Table 1). The combination of parameters used in the original design corresponds to sets H6 (in service state: $c^{\prime}=0, \varphi^{\prime}=44^{\circ}$ ) and $\mathrm{H} 36$ (during construction: $c^{\prime}=50 \mathrm{kPa}, \varphi^{\prime}=44^{\circ}$ ). The material properties of steel and concrete have been assumed deterministic with the values used in the original design. The rest of the parameters of the rock mass are taken with average values common in the area, and are the same for all $\left(c^{\prime}, \varphi^{\prime}\right)$ pairs (Table 2).

The first numerical analysis with the computer code PARATIE ${ }^{\mathrm{TM}}$ [34] has been performed to evaluate the loads acting on the wall (bending moment, shear forces), its lateral deformation, and the loads on the tiebacks. PARATIE ${ }^{\mathrm{TM}}$ is a nonlinear finite element code for the analysis of flexible retaining walls during multiple construction phases. Several components can be activated and/or removed during the analysis, such as anchors, struts, 
fixed or flexible supports, external loadings, etc. If relevant, water table and seepage forces may also be included. This computer code performs the numerical analysis with the following premises: (a) the problem is assumed to be plane-strain: degrees of freedom are lateral displacements and out-of-plane rotations; vertical movements are automatically linked, and therefore the axial forces on the wall are not computed; (b) the flexible wall is simulated by a series of vertical beam elements; (c) the earth pressure can be applied on both sides of the wall (active or passive), and it is simulated by a double layer of elasto-plastic springs connected to the nodes on the wall; and (d) the sustaining elements (tiebacks, anchorages, struts, etc.) are simulated by springs applied to nodes on the wall.

The response of the wall is obtained after numerical simulation of the construction sequence including construction of the wall, excavation and installation of the rows of tiebacks. All phases reproduce as accurately as possible the contractor-supplied load history of the structural elements. The sequence is as follows (note that steps 6 and 7 were never reached during the actual execution of the wall):

1. Application of the pressure from the back slope.

2. Excavation of $1 \mathrm{~m}$, to level +1.00 , and construction of the upper row of anchored tiebacks.

3. Excavation of $1 \mathrm{~m}$, to level 0.00

4. Excavation of $1 \mathrm{~m}$, to level -1.00

5. Excavation of $2 \mathrm{~m}$, to level -3.00 (actual failure occurred during this step)

6. Excavation of $2 \mathrm{~m}$, to level -5.00 , and construction of the lower row of anchored tiebacks.

7. Excavation of $2.15 \mathrm{~m}$ to level -7.15

Knowing that failure did occur, and that it happened after approximately $5 \mathrm{~m}$ of excavation, it is possible to estimate the range of the actual, or most likely, $\left(c^{\prime}, \varphi^{\prime}\right)$ pairs from the results of the numerical analysis, by recording the $\left(c^{\prime}, \varphi^{\prime}\right)$ combinations for which the finite element analysis indicates that failure has been reached, or else for which the method does not converge in one of the construction steps (lack of convergence is an indicator of near-failure conditions).

To investigate the sensitivity of the failure on the back slope height which was incorrect in the original design, the previous seven-step construction sequence was applied with two values of back slope height: $10 \mathrm{~m}$ (the actual value) and $5 \mathrm{~m}$ (original design), for comparison purposes and also to evaluate how sensitive to these variable are the failure conditions. The 
results show that to reach failure as it happened, the strength parameters must have been $\boldsymbol{c}^{\prime} \approx$ $\mathbf{0} \mathrm{kPa}$ and $\boldsymbol{\varphi}^{\prime} \approx \mathbf{2 5}^{\mathbf{0}}-\mathbf{3 0}^{\mathbf{0}}$ for the actual $10 \mathrm{~m}$ height, and $\boldsymbol{c}^{\prime} \approx \mathbf{0} \mathrm{kPa}$ and $\boldsymbol{\varphi}^{\prime} \leq \mathbf{2 0 ^ { \circ }}$ for the incorrect $5 \mathrm{~m}$ used in the design. In both cases the estimated values of the strength parameters are much lower than the ones used in the original design $\left(\boldsymbol{c}^{\prime}=\mathbf{5 0} \mathrm{kPa}, \boldsymbol{\varphi}^{\prime}=\mathbf{4 4}^{\mathbf{0}}\right)$. With these parameters failure could not have happened even with the actual back slope height. The results also indicate that with $5 \mathrm{~m}$ of back slope height the failure could not have happened with reasonable values of the strength parameters in the range indicated above.

Therefore, the actual back slope height of $10 \mathrm{~m}$ and dry soil (because water did not play a significant role) have been adopted to analyse the failure with the $36\left(c^{\prime}, \varphi^{\prime}\right)$ pairs with ranges defined in Table 1. Figure 10 shows the limiting envelope of these $\left(c^{\prime}, \varphi^{\prime}\right)$ pairs considered in the failure analysis. Pairs outside the shaded area do not lead to failure and therefore cannot be the actual strength parameters since failure did happen. This shows that the design strength was largely overestimated, since the $\left(c^{\prime}, \varphi^{\prime}\right)$ pair used in the design is well outside the shaded area. The results suggest that the strength parameter sets that most likely represent the in situ conditions are $\mathrm{H} 3$ or $\mathrm{H} 9$ (Table 1), with $c^{\prime}=0$ or $10 \mathrm{kPa}$ respectively, both with $\varphi^{\prime}=30^{\circ}$.

The failure conditions of the tiebacks were also analysed. The tiebacks were made of steel cable with a load capacity of $150 \mathrm{kN}$ per cable. Each tieback on the upper row consisted of two cables, with a total load capacity of $300 \mathrm{kN}$. With a separation of $3 \mathrm{~m}$, the total admissible force on the tiebacks, per unit length, was $100 \mathrm{kN} / \mathrm{m}$. Figure 11 shows the predicted load on the upper tieback row at the end of the construction for each $\left(c^{\prime}, \varphi^{\prime}\right)$ pair in Table 1, with the C1 load setup. This figure shows how the load is higher with lower strength parameters, since then the lateral pressure on the wall is much larger. The figure shows also that there are only six $\left(c^{\prime}, \varphi^{\prime}\right)$ pairs for which the load on the tiebacks remains below 100 $\mathrm{kN} / \mathrm{m}$ during all construction steps, including those that were never executed because the wall failed before: H24 (30 kPa, 44 $)$, H29 (40 kPa, 40 $), H 30\left(40 \mathrm{kPa}, 44^{\circ}\right), \mathrm{H} 34\left(50 \mathrm{kPa}, 35^{\circ}\right)$, $\mathrm{H} 35\left(50 \mathrm{kPa}, 40^{\circ}\right)$ and $\mathrm{H} 36\left(50 \mathrm{kPa}, 44^{\circ}\right)$.

Figure 12 shows the value of the load on the same row of tiebacks at the end of step 5, which was the last actually executed and during which failure occurred. Note that for some of the $\left(c^{\prime}, \varphi^{\prime}\right)$ pairs failure happens before reaching this step. Considering only the construction steps that were actually executed before failure (step 5), the load on the tiebacks remains less than $100 \mathrm{kN} / \mathrm{m}$ with four more $\left(c^{\prime}, \varphi^{\prime}\right)$ pairs: H18 $\left(20 \mathrm{kPa}, 44^{\circ}\right), \mathrm{H} 23\left(30 \mathrm{kPa}, 40^{\circ}\right), \mathrm{H} 28(40$ $\left.\mathrm{kPa}, 35^{\circ}\right)$ and $\mathrm{H} 33\left(50 \mathrm{kPa}, 30^{\circ}\right)$. These latter $\left(c^{\prime}, \varphi^{\prime}\right)$ pairs are outside the range considered 
most likely. Therefore, since for the remaining $\left(c^{\prime}, \varphi^{\prime}\right)$ pairs the load on the tiebacks is larger than the maximum admissible, it may be concluded that at the time of failure the load on the tiebacks was larger than its yield strength, and the cables were fully in the plastic regime.

The second numerical analysis has been carried with the computer code DRAC [35], a general purpose finite element system developed specifically to perform analysis of geotechnical engineering problems. DRAC is a nonlinear code allowing 2D and 3D analysis, and includes zero thickness interface elements used in solving soil and rock mechanics problems to simulate discontinuities and contact surfaces. Also available are rod elements, used in the simulation of anchorages, tiebacks and struts. For the current analysis, a 2D finite element model in plane strain has been developed (Figure 13).

Computations have been performed for each of the $\left(c^{\prime}, \varphi^{\prime}\right)$ pairs in Table 1 with the primary purpose of finding the most likely failure surface linked to the previous numerical analysis, and also to support the results described before. The analysis with code DRAC has not been carried out, however, to the fullest extent possible with the code, because a threedimensional analysis of the wall and foundation mass would be necessary to fully understand the conditions of failure. However, this would not be justifiable for the objectives of the investigation in this case because of the computational cost involved.

The sequence of excavation and construction of the micropiles and tiebacks has been simulated in 8 numerical steps, graphically described in Figure 14, with the C1 load setup. The numerical steps do not necessarily coincide with the construction steps defined previously. Thus, numerical step 1 (Figure 13) is the generation of the whole finite element mesh and the assigning of the initial stresses at the integration points. Although failure occurred when excavation reached the depth corresponding to numerical step 7 , the analysis has been carried out to the end of the described sequence, except when prevented by lack of convergence, an indicator that failure conditions were reached.

The numerical model is made of 1809 nodes, with 3261 triangular and 33 quadrilateral linear elements to simulate the rock mass, 73 interface elements to simulate the contact between the micropile wall and the ground, and two rod elements to simulate the two rows of tiebacks. The mesh is denser near the micropile wall, where failure is expected to occur. The rock mass is modelled with a Mohr-Coulomb material law, with the cohesion and friction angle corresponding to each of the $\left(\boldsymbol{c}^{\prime}, \boldsymbol{\varphi}^{\prime}\right)$ pairs in Table 1 . The rest of the material 
parameters are given in Table 2. For simplicity, and because lack of actual data, $K_{0}$ prior to excavation has been assumed to be 0.5 in all cases.

The tiebacks were simulated by rod elements, fixed at their ends to the wall elements and to the rock mass. For simplicity, no interaction between the rod elements and the surrounding material is modelled. The rod elements, as well as the elements representing the wall were modelled with a linear elastic material law.

In general, the results obtained from the finite element analysis with DRAC are in good agreement with the results from the analysis with PARATIE ${ }^{\mathrm{TM}}$. Especially illustrative are the results showing the plastic deformation contours (Figure 15), which can be used to locate the position of the failure surface, and the deformed mesh (Figure 16), showing the curvature of the deformed micropile wall, a qualitative measure of the existing bending moments. High values of plastic deformation indicate the zones where the material has reached its yield limit. When this zone with high plastic deformation extends to a large volume, it indicates that the material has reached a global collapse condition. Figure 15 shows the extent of the plastic zone at the end of numerical step 7 for some selected $\left(c^{\prime}, \varphi^{\prime}\right)$ pairs. The figure shows that for low values of cohesion and friction angle, the volume of the plastic zone is large indicating that the ground behind the micropile wall has failed completely, whereas this volume decreases when the values of these parameters increase. In particular, for the values of $c^{\prime}$ and $\varphi^{\prime}$ used in the original design of the retaining wall $\left(c^{\prime}=50 \mathrm{kPa}\right.$ and $\varphi^{\prime}=44^{\circ}$, respectively, set H36) no significant plastic zone develops during excavation.

The main conclusion of the numerical analysis using codes PARATIE ${ }^{\mathrm{TM}}$ and DRAC is that if the actual strength parameters had been the ones used in the original design, failure would never have occurred. Failure requires that the actual strength parameters be significantly lower, in the range obtained from this analysis.

\section{Discussion}

The two main issues investigated with the numerical analysis, regarding the failure of the wall, are the strength of the rock mass and the back slope height. It seems likely that the water table was deep and therefore did not play a role in the failure. The construction process did follow adequately the design specifications and therefore poor construction techniques were ruled out as possible cause of failure. Comparing the results obtained in this work with the original design, the following points can be made: 


\subsection{Strength parameters of the rock mass}

The geotechnical report on which the original design was based specified zero cohesion and a friction angle of $44^{\circ}$. This was based on a laboratory analysis of a single sample taken from a depth of 2.3 to $2.6 \mathrm{~m}$, about $35 \mathrm{~m}$ from where the wall would be constructed.

It seems rather risky to have adopted, as representative of all materials, the values obtained from a single sample taken at a considerable distance, since the geological and geotechnical characteristics are very different: the sample used for testing was a clayey gravel (GP-GC) with a natural water content of $6 \%$ and a dry density of $20 \mathrm{kN} / \mathrm{m}^{3}$, while the rock mass in the failure zone consists of slates with a natural water content of $0.05 \%$ and dry density of $26 \mathrm{kN} / \mathrm{m}^{3}$. It seems unlikely that the strength of the latter material was the same as the one used in the laboratory tests. It seems also risky to have taken values as high as the ones in the original design, even for a temporary wall, without taking into account relevant warnings issued in the geotechnical report about using those values with caution.

The present analysis shows that for dry material failure requires the strength parameters to be $c^{\prime} \approx 0 \mathrm{kPa}$ and $\varphi^{\prime} \approx 25^{\circ}-30^{\circ}$. The friction angle is considerably smaller than the value used in the original design and the cohesion is almost zero, compared with the $50 \mathrm{kPa}$ assumed in the original design. With this latter value of cohesion, the numerical analysis predicts that failure conditions are never reached.

\subsection{Lateral pressure on the wall due to the back slope surcharge}

The original topographic survey did not provide information of the topography beyond the property limits. Because of that, the ground surface in the original project was assumed horizontal with a back slope height of $5 \mathrm{~m}$. After failure, a new topographic survey, that covered the zone of the amusement park beyond the property limits, showed an uphill back slope with a height of $10 \mathrm{~m}$, double of what was assumed in the design. The numerical analysis shows that with a back slope height of $5 \mathrm{~m}$ and using $c^{\prime}=0 \mathrm{kPa}$ and $\varphi^{\prime}=30^{\circ}$, the safety factor on $\varphi^{\prime}$ ranges from 1.2 to 1.5 depending on the presence or not of water in the ground.

\section{Summary and conclusions}

Numerical analysis using the Finite Element Method has been used to determine the causes and mechanisms that lead to the failure of a temporary micropile retaining wall during excavation and to estimate the actual strength of the rock mass by means of a simplified 
backanalysis. A sensitivity analysis has also been carried on the back slope height. The main conclusions can be summarized as follows:

1. The main cause of failure was the overestimation of the rock mass strength. The friction angle used in the design was about 50\% larger than the most likely value suggested from the present analysis. The cohesion $(50 \mathrm{kPa})$ was also largely overestimated, since laboratory tests provided a near-zero value for that parameter. The present study shows as well that the most likely value for the cohesion was near $0 \mathrm{kPa}$. In general, failure appears to be more sensitive to the friction angle than to cohesion.

2. A second cause of failure was the underestimation, during design, of the lateral loads on the wall. The reason was an incomplete topographic survey that did not extend beyond the property limits, and lead to an underestimation of the back slope height. Therefore, the loads on the tiebacks were also underestimated and the tiebacks failed because the transmitted loads were larger than their design yield strength. After failure of the tiebacks, the wall rotated and translated pulling out the remaining tiebacks that did not fail previously, and triggered the motion of the ground behind the wall. If the strength of the rock mass had been correct, this underestimation of loads probably would have had no consequences, according to the results of the present work. However, it did have an impact, since the actual strength was much lower than the one used in the original design.

3. The events described in this paper and the subsequent finite element analysis demonstrate that knowledge of reliable ground properties as well as of good geometric and morphologic ground characteristics is crucial for sound design of geotechnical structures. Failure to obtain this information through sufficient testing and surveying is bound to lead to failures such as the one described in this paper with considerable economic losses, and in the worst cases with possible injuries or fatalities, which imply far more expenses than the savings for not carrying an extensive investigation campaign before the design stages.

\section{Acknowledgment}

The author wishes to thank Prof. Jordi Corominas for his help and comments related to the geologic characteristics of the site. 


\section{References}

[1] Prat PC. Failure of a micro-pile wall during remodelling of a hotel: a backanalysis. In: Triantafyllidis T, editor. Numerical Modelling of Construction Processes in Geotechnical Engineering for Urban Environment: Taylor \& Francis (Balkema), 2006. p. 273-80.

[2] Veder C. Process construction of diaphragm impermeable walls in large foundations using bentonite. Proceedings 3rd International Conference on Soil Mechanics Found Engrg. Zürich1953. p. 91-4.

[3] Armour T, Groneck P, Keelev J, Sharma S. Micropile Design and Construction Guidelines Implementation Manual. FHWA Office of Technology Applications, 2000.

[4] Bruce DA, Dimillio A, Juran I. Micropiles: the State of Practice. Part I: Characteristics, definition and classification. Journal of Ground Improvement. 1997;1(1):25-35.

[5] Goldberg DT, Jaworski WE, Gordon MD. Lateral Support Systems and Underpinning. FHWA Offices of Research and Development, 1976.

[6] Juran I, Bruce DA, Dimillio A, Benslimane A. Micropiles: the State of Practice. Part II: Design of single micropiles and groups and networks of micropiles. Journal of Ground Improvement. 1999;3(1):89-110.

[7] Liew SS, Fong CC. Design and Construction of Micropiles. Geotechnical Course for Pile Foundations Design and Construction: Gue \& Partners Sdn Bhd, Kuala Lumpur, Malaysia, 2003. p. 1-49.

[8] Lizzi F. The Pali Radice (Root Piles). Symposium on Soil and Rock Improvement Techniques, Including Geotextiles, Reinforced Earth, and Modern Piling Methods. Bangkok1982. p. Paper D3.

[9] Lizzi F. Static restoration of monuments. Genoa, Italy: Sagep Publisher, 1982.

[10] Macklin PR, Berger D, Zietlow W, Herring W, Cullen J. Case History: Micropile use for temporary excavation support. In: Turner JP, Mayne PW, editors. Geo-Support 2004: Drilled Shafts, Micropiling, Deep Mixing, Remedial Methods, and Specialty Foundation Systems. Orlando, Florida: ASCE, 2004. p. 653-61.

[11] Macnab A. Earth retention systems handbook. New York: McGraw-Hill, 2002.

[12] Pinto A, Ferreira S, Barros V. Underpinning solutions of historical constructions. In: Lourenço PB, Roca P, editors. Third International Seminar on Consolidation and Strengthening Techniques. Guimarães, Portugal2001. p. 1003-12. 
[13] Schneebeli G. Les parois moulées dans le sol. Paris: Éditions Eyrolles, 1972.

[14] Sivakumar GL, Srinivasa BR, Murthy DSN, Nataraj MS. Bearing capacity improvement using micropiles: a case study. In: Turner JP, Mayne PW, editors. Geo-Support 2004: Drilled Shafts, Micropiling, Deep Mixing, Remedial Methods, and Specialty Foundation Systems. Orlando, Florida: ASCE, 2004. p. 692-9.

[15] Veder C. Excavation of trenches in the presence of bentonite suspensions for the construction of impermeable and load-bearing diaphragms. Symposium on Grouts and Drilling Muds in Engineering Practice. London: Butterworths, 1963. p. 181-8.

[16] Veder C. Closing address. Diaphragm Walls and Anchorages. London: Institution of Civil Engineers, 1975. p. 221-5.

[17] De Moor EK. An analysis of bored pile/diaphragm wall installation effects. Géotechnique. 1994;44(1):341-7.

[18] Goh ATC. Behaviour of cantilever retaining walls. Journal of Geotechnical Engineering, ASCE. 1993;119(11):1751-71.

[19] Addenbrooke TI, Potts DM, Dabee B. Displacement flexibility number for multipropped retaining wall design. Journal of Geotechnical and Geoenvironmental Engineering ASCE. 2000;126(718-26.

[20] Nadukuru SS, Michalowski RL. Arching in distribution of active load on retaining walls. Journal of Geotechnical and Geoenvironmental Engineering ASCE. 2012;138(5):575-84.

[21] Clayton CRI, Symons IF. The pressure of compacted fill on retaining walls. Géotechnique. 1992;42(1):127-30.

[22] Gunn MJ, Clayton CRI. Installation effects and their importance in the design of earthretaining structures. Géotechnique. 1992;42(137-41.

[23] Symons IF, Potts DM, Charles JA. Predicted and measured behaviour of a proposed embedded retaining wall in stiff clay. In: ISSMFE, editor. Proceedings 11th International Conference on Soil Mechanics Found Engrg. San Francisco, USA1985. p. 2265-8.

[24] Abramento M, Whittle AJ. Analysis of pullout tests for planar reinforcement in soil. Journal of Geotechnical Engineering, ASCE. 1995;121(6):476-85.

[25] Abramento M, Whittle AJ. Experimental evaluation of pullout analyses for planar reinforcements. Journal of Geotechnical Engineering, ASCE. 1995;121(6):486-92. 
[26] Alonso EE, Gens A, Josa A. A constitutive model for partially saturated soils. Géotechnique. 1990;40(405-30.

[27] Schrefler BA, Simoni L, Majorana CE. A general model for the mechanics of saturatedunsaturated porous materials. Materials \& Structures RILEM. 1989;22(323-34.

[28] Fredlund DG, Rahardjo H. Soil mechanics for unsaturated soils: John Wiley and Sons, Inc., 1993.

[29] Vanapalli SK, Fredlund DG, Pufhal DE, Clifton AW. Model for the prediction of shear strength with respect to soil suction. Canadian Geotechnical Journal. 1996;33(3):379-92.

[30] Bieniawski ZT. Engineering rock mass classification. New York: John Wiley \& Sons, 1989.

[31] Hoek E, Bray JW. Rock slope engineering. London: Spon Press - Institution of Mining and Metallurgy, 1981.

[32] Hoek E, Carranza-Torres C, Corkum B. Hoek-Brown failure criterion - 2002 edition. In: Hammah RE, editor. 5th North American Rock Mechanics Simposium. Toronto2002. p. 26771.

[33] Blum H. Einspannungsverhältnisse bei Bohlwerken. Berlin: Ernst \& Sohn, 1931.

[34] CEAS. PARATIE for Windows User's Manual. 6.1 ed. Milano, Italy: Centro di Analisi Sttrutturale, s.r.1., 2003.

[35] Prat PC, Gens A, Carol I, Ledesma A, Gili JA. DRAC: A computer software for the analysis of rock mechanics problems. In: Liu H, editor. Application of computer methods in rock mechanics. Xian, China: Shaanxi Science and Technology Press, 1993. p. 1361-8. 


\section{LIST OF FIGURES}

Figure 1. Schematic sequence of the excavation: a) execution of the micropiles; b) and c) intermediate stages including excavation and execution of the tiebacks; d) final state.

Figure 2. Sketch of the area showing the original position of the collapsed wall. Section $\mathrm{AA}^{\prime}$ is shown in Figure 5.

Figure 3. Topographic map (detail) used in the design of the micropile wall. The survey did not include the adjacent property (to the West), thus incorrectly showing a horizontal surface (at $+494.00 \mathrm{~m}$ ) beyond the property limits.

Figure 4. Topographic map (detail) from the new survey performed after the collapse, showing the true topographic surface in the adjacent property, the original location of the failed micropile wall (thick line from top left to bottom right) and the position of the failed elements after collapse.

Figure 5. Typical cross-section used in the analysis ( $\mathrm{AA}^{\prime}$ in Figure 2)

Figure 6. View of the excavation zone before the wall was initiated. The location of the failure is on the right of the image.

Figure 7. View of the collapsed wall. The intact part of the wall with the cap beam can be seen on the left, and the failed part on the right.

Figure 8. Detail of the failed wall. Parts of the broken piles and cap beam can be seen scattered on the ground surface.

Figure 9. Collapse mechanism: (a) initial conditions; (b) a plastic hinge forms, arching occurs behind the wall and the ground cannot resist; (c) lateral deformation of the pile begins with the tieback within its strength limit; (d) large lateral deformation and failure of the tieback and pile.

Figure 10. Limiting envelope of strength parameters combinations leading to failure.

Figure 11. Predicted load on the upper tieback row at the end of construction for all strength parameters combinations analyzed. Missing points indicate failure before reaching this stage.

Figure 12. Predicted load on the upper tieback row at the end of construction stage 5 when the actual collapse occurred. Missing points indicate failure before reaching this stage.

Figure 13. Initial (step 1) finite element mesh used with DRAC

Figure 14. Excavation sequence with DRAC (step numbers refer to the numerical analysis, not to the construction sequence)

Figure 15. Extent of the plastic zone obtained with DRAC near the micropile wall after step 7 for the selected sets of strength parameters indicated

Figure 16. Deformed mesh obtained with DRAC near the micropile wall after step 7 for the selected sets of strength parameters indicated (magnification: $100 \times$ ) 
Table 1. Definition of combinations of strength parameters used in the analysis

\begin{tabular}{c|cccccc}
\hline$c^{\prime}$ & $0 \mathrm{kPa}$ & $10 \mathrm{kPa}$ & $20 \mathrm{kPa}$ & $30 \mathrm{kPa}$ & $40 \mathrm{kPa}$ & $50 \mathrm{kPa}$ \\
\hline$\varphi^{\circ}$ & & & & & & \\
$25^{\circ}$ & $\mathrm{H} 01$ & $\mathrm{H} 07$ & $\mathrm{H} 13$ & $\mathrm{H} 19$ & $\mathrm{H} 25$ & $\mathrm{H} 31$ \\
$30^{\circ}$ & $\mathrm{H} 03$ & $\mathrm{H} 14$ & $\mathrm{H} 20$ & $\mathrm{H} 26$ & $\mathrm{H} 32$ \\
$35^{\circ}$ & $\mathrm{H} 04$ & $\mathrm{H} 10$ & $\mathrm{H} 15$ & $\mathrm{H} 21$ & $\mathrm{H} 27$ & $\mathrm{H} 33$ \\
$40^{\circ}$ & $\mathrm{H} 05$ & $\mathrm{H} 11$ & $\mathrm{H} 17$ & $\mathrm{H} 23$ & $\mathrm{H} 28$ & $\mathrm{H} 34$ \\
$44^{\circ}$ & $\mathrm{H} 06$ & $\mathrm{H} 12$ & $\mathrm{H} 18$ & $\mathrm{H} 24$ & $\mathrm{H} 30$ & $\mathrm{H} 35$ \\
\hline
\end{tabular}

Table 2. Fixed material parameters

\begin{tabular}{lr}
\hline Parameter & \multicolumn{1}{c}{ Value } \\
\hline Steel elasticity modulus, $E_{s}$ & $2.1 \times 10^{5} \mathrm{MPa}$ \\
Concrete elasticity modulus, $E_{c}$ & $2.5 \times 10^{4} \mathrm{MPa}$ \\
Virgin modulus of rock, $E_{v}$ & $30 \mathrm{MPa}$ \\
Unloading/reloading modulus of rock, $E_{u r}$ & $50 \mathrm{MPa}$ \\
Dry specific weight of the rock above the & $20 \mathrm{kN} / \mathrm{m}^{3}$ \\
$\quad$ top of the micropiles, $\gamma_{d l}$ & \\
Dry specific weight of the rock below the & $24 \mathrm{kN} / \mathrm{m}^{3}$ \\
$\quad$ top of the micropiles, $\gamma_{d}$ & 0.5 \\
$K_{0}$ coefficient & \\
\hline
\end{tabular}



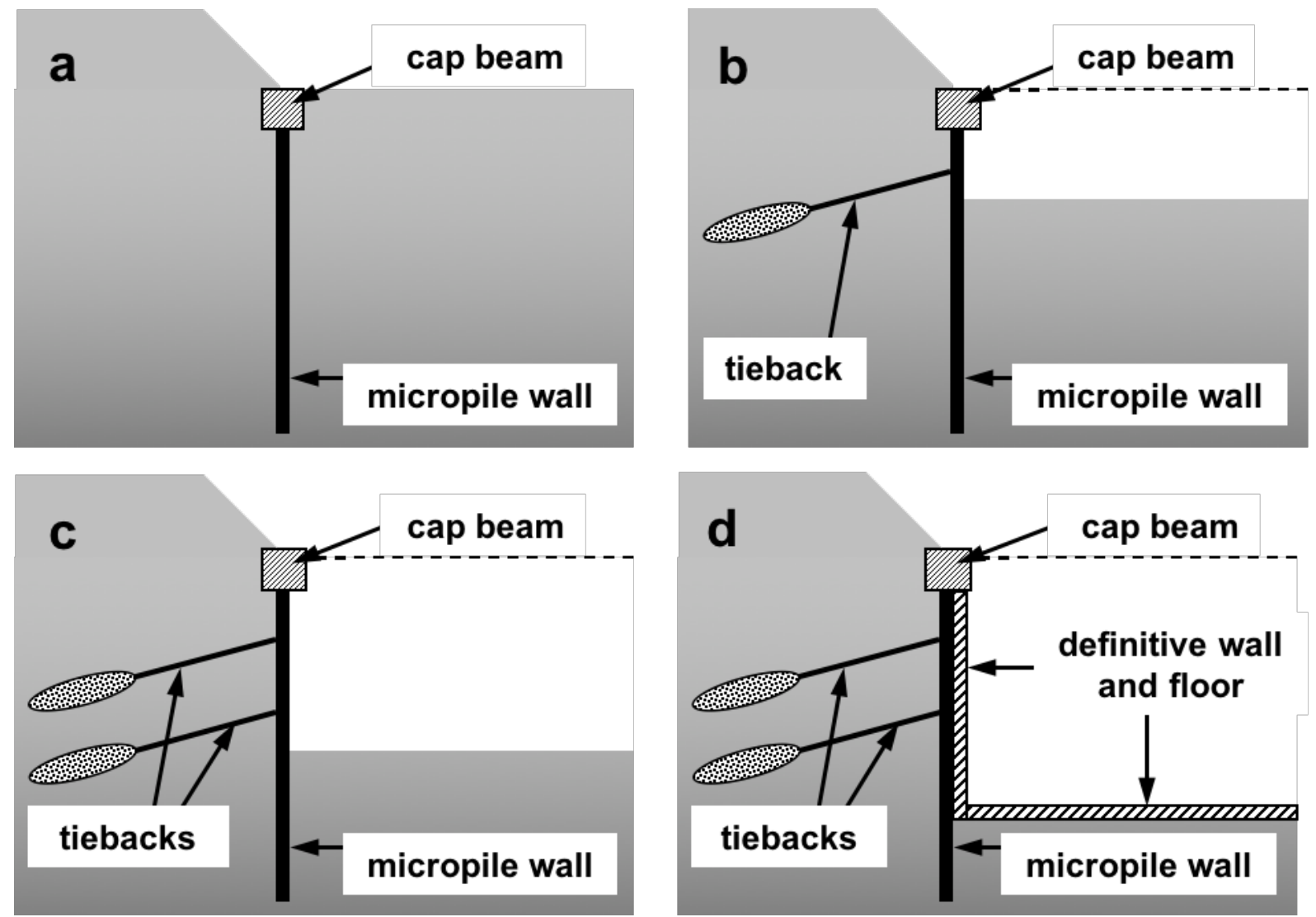

Figure 1. Schematic sequence of the excavation: a) execution of the micropiles; b) and c) intermediate stages including excavation and execution of the tiebacks; d) final state. 


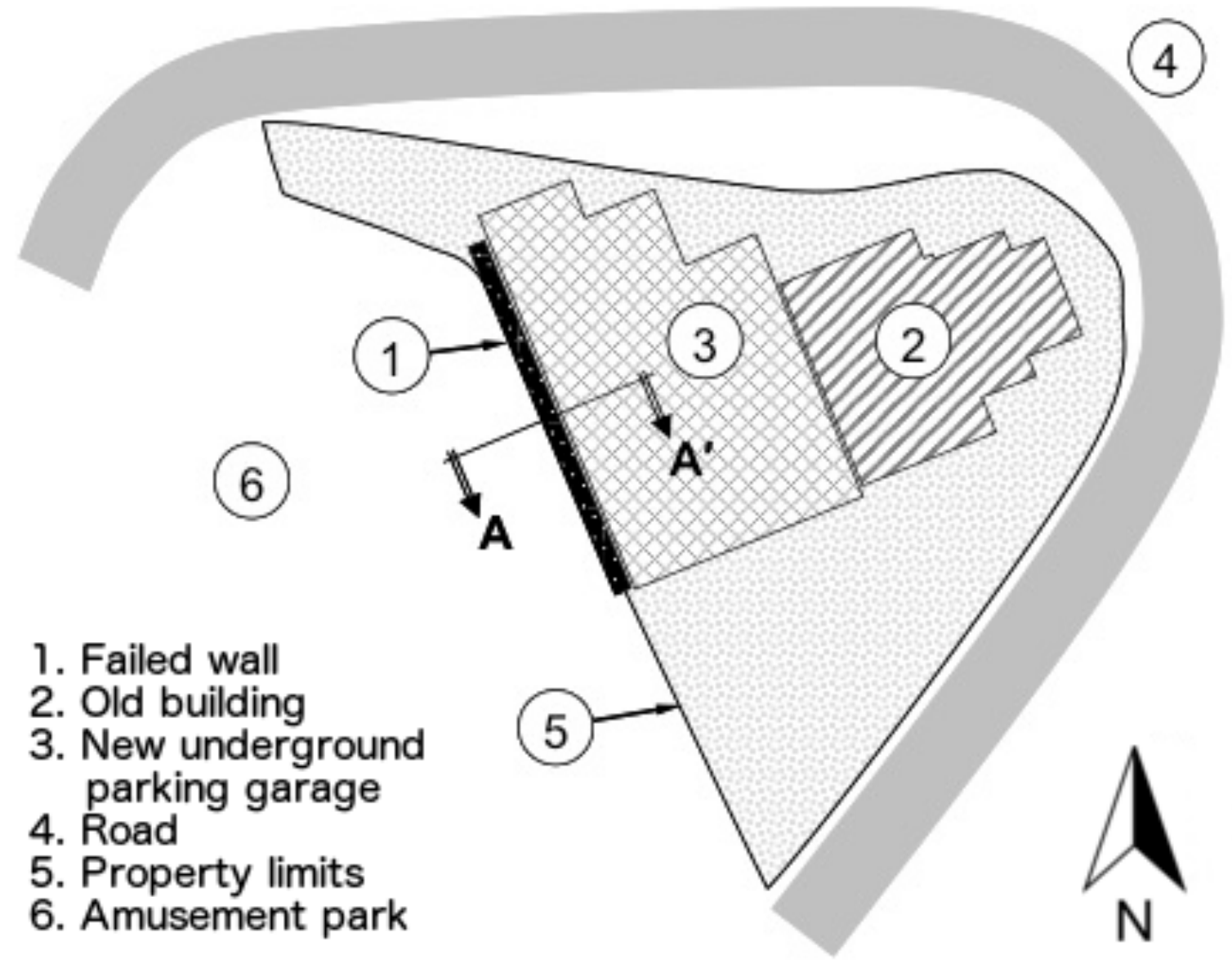

Figure 2. Sketch of the area showing the original position of the collapsed wall. Section AA' $^{\prime}$ is shown in Figure 5. 


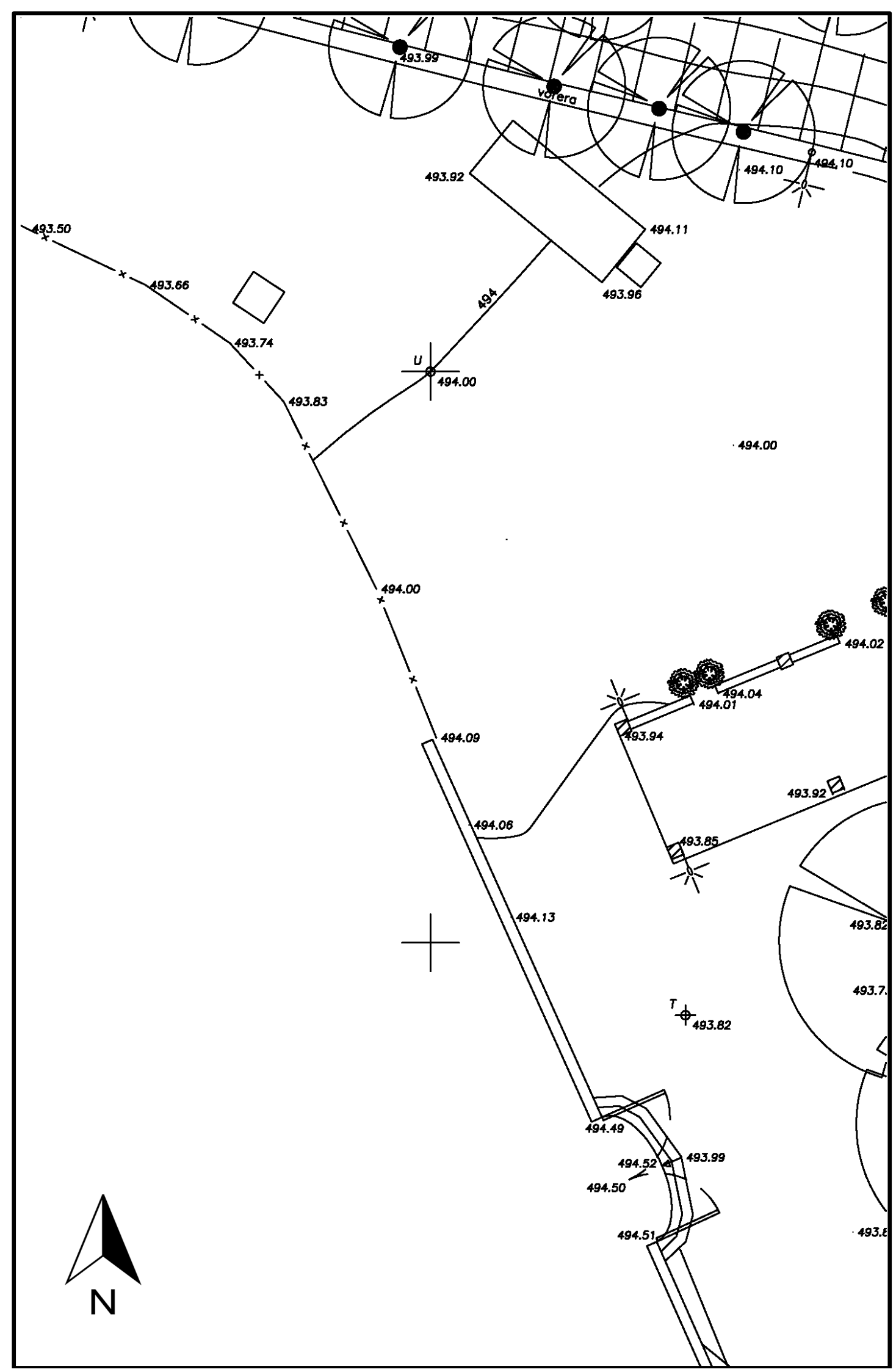

Figure 3. Topographic map (detail) used in the design of the micropile wall. The survey did not include the adjacent property (to the West), thus incorrectly showing a horizontal surface (at $+494.00 \mathrm{~m}$ ) beyond the property limits. 


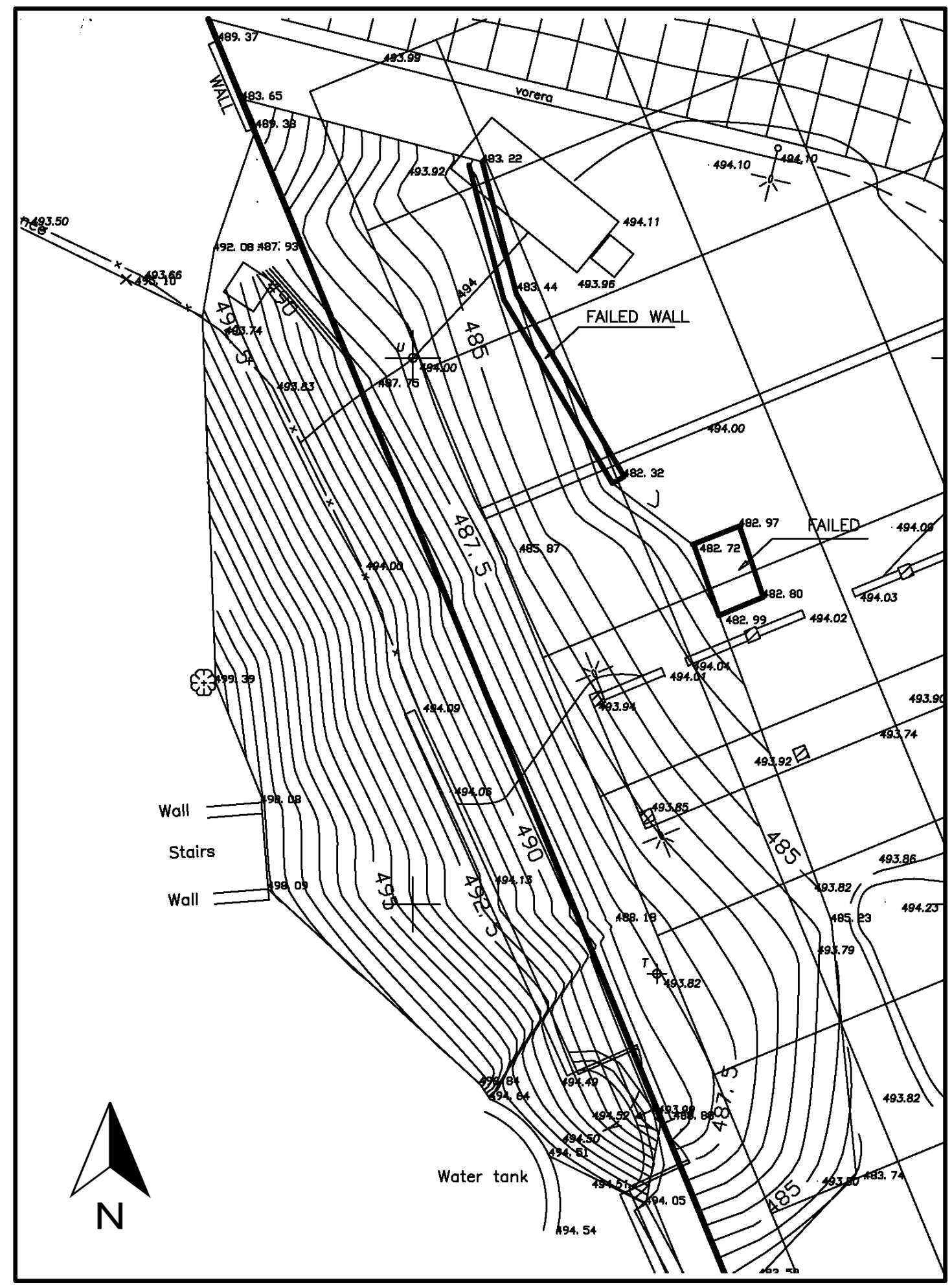

Figure 4. Topographic map (detail) from the new survey performed after the collapse, showing the true topographic surface in the adjacent property, the original location of the failed micropile wall (thick line from top left to bottom right) and the position of the failed elements after collapse. 


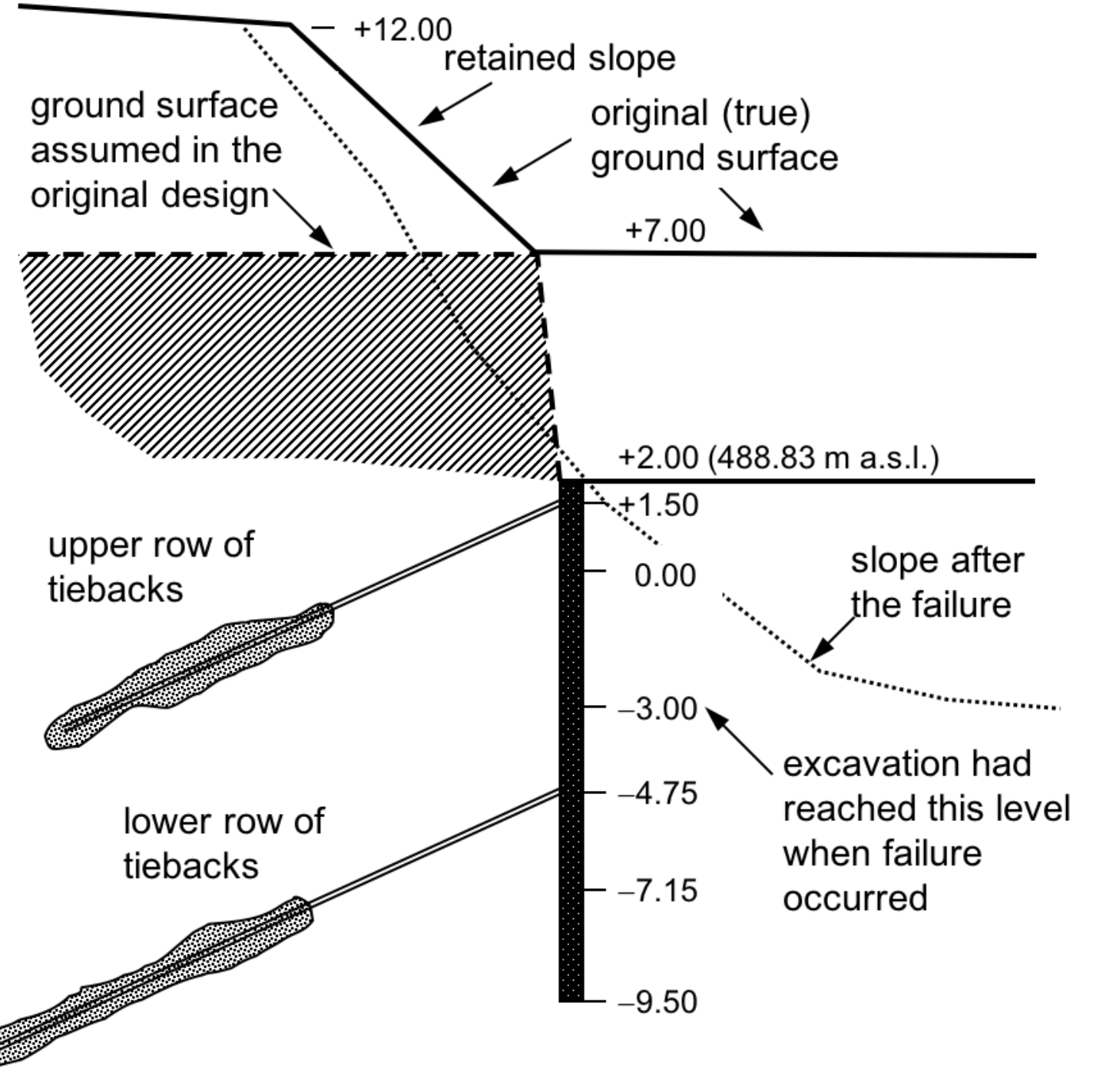

Figure 5. Typical cross-section used in the analysis (AA' in Figure 2) 


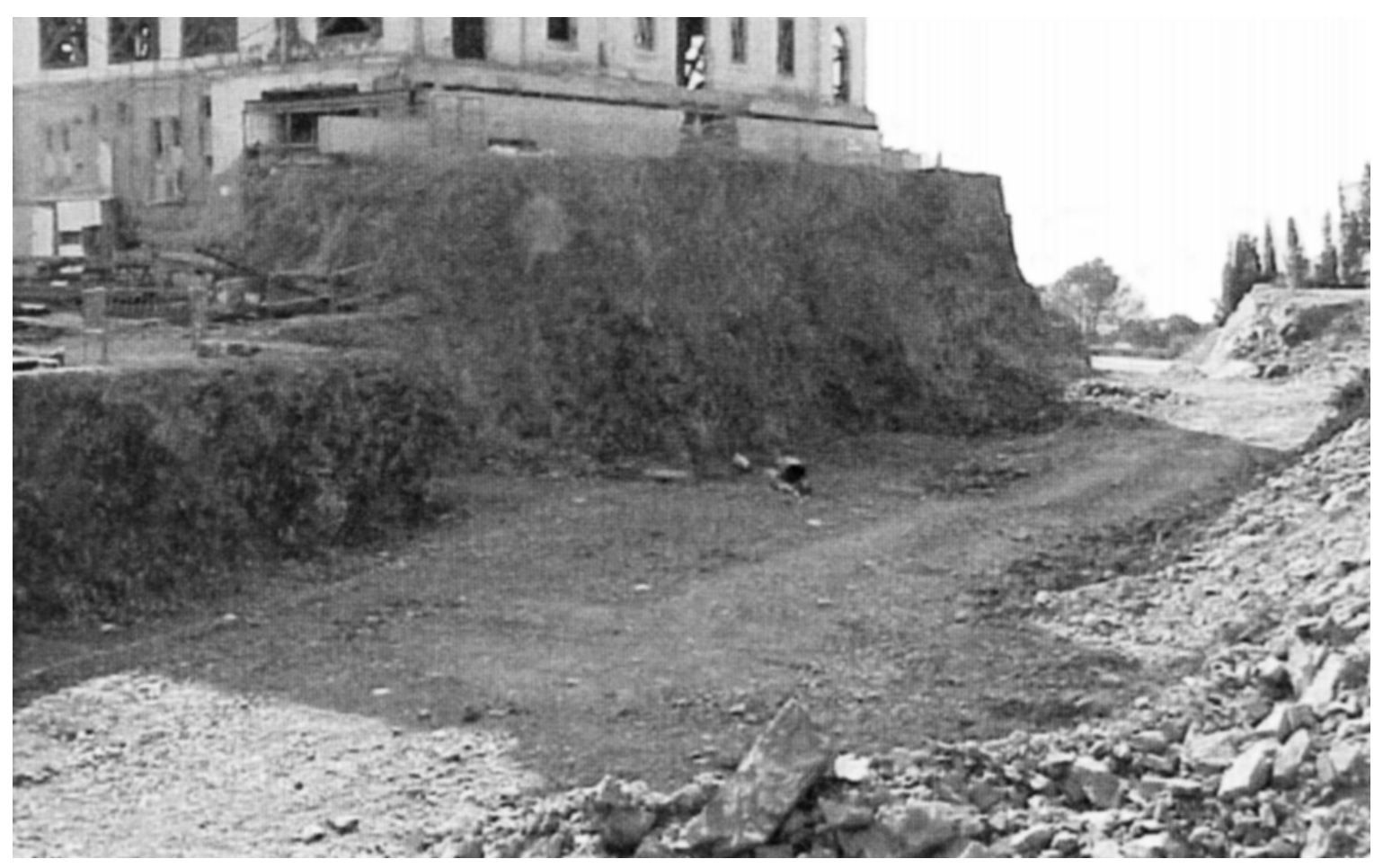

Figure 6. View of the excavation zone before the wall was initiated. The location of the failure is on the right of the image.

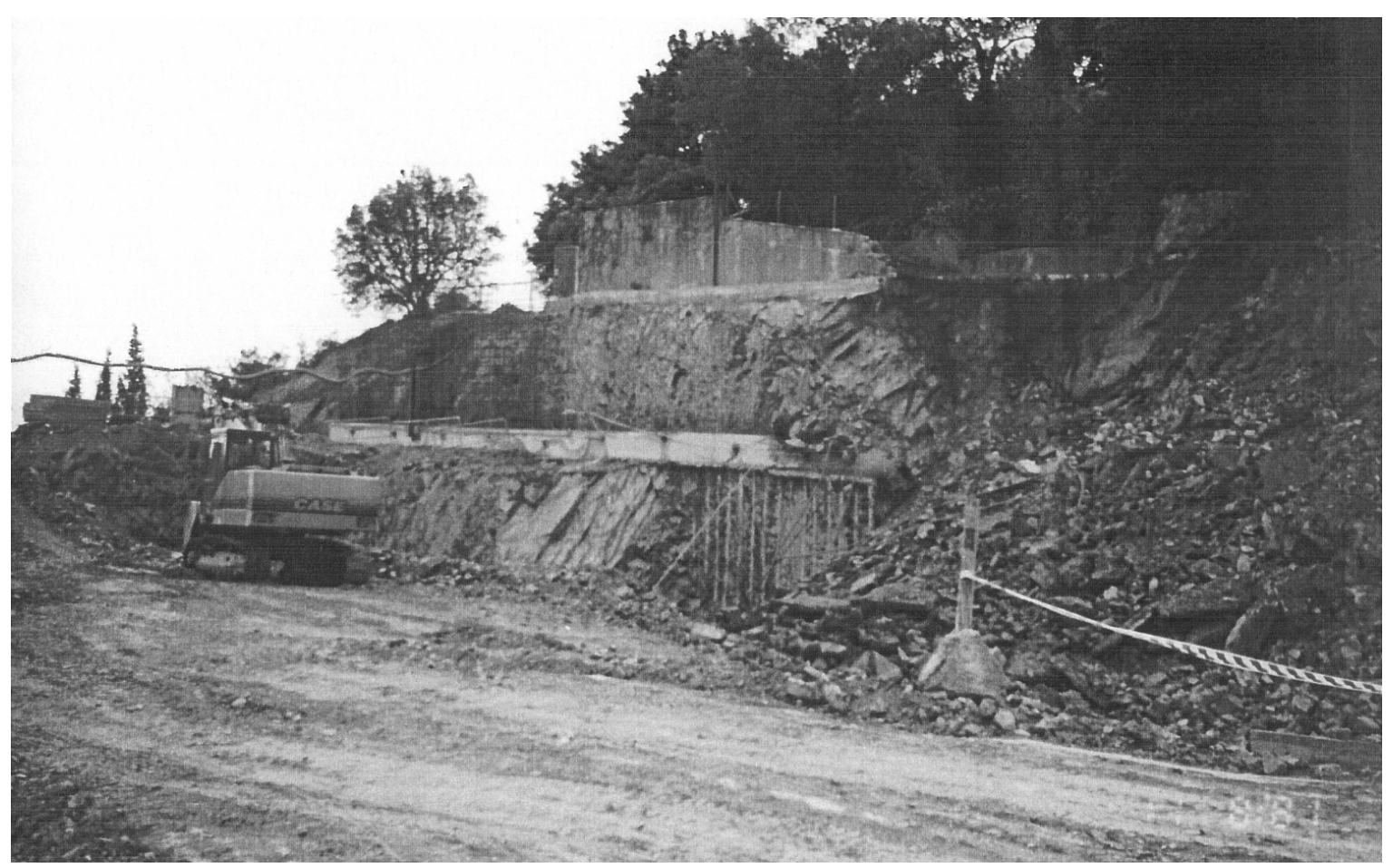

Figure 7. View of the collapsed wall. The intact part of the wall with the cap beam can be seen on the left, and the failed part on the right. 

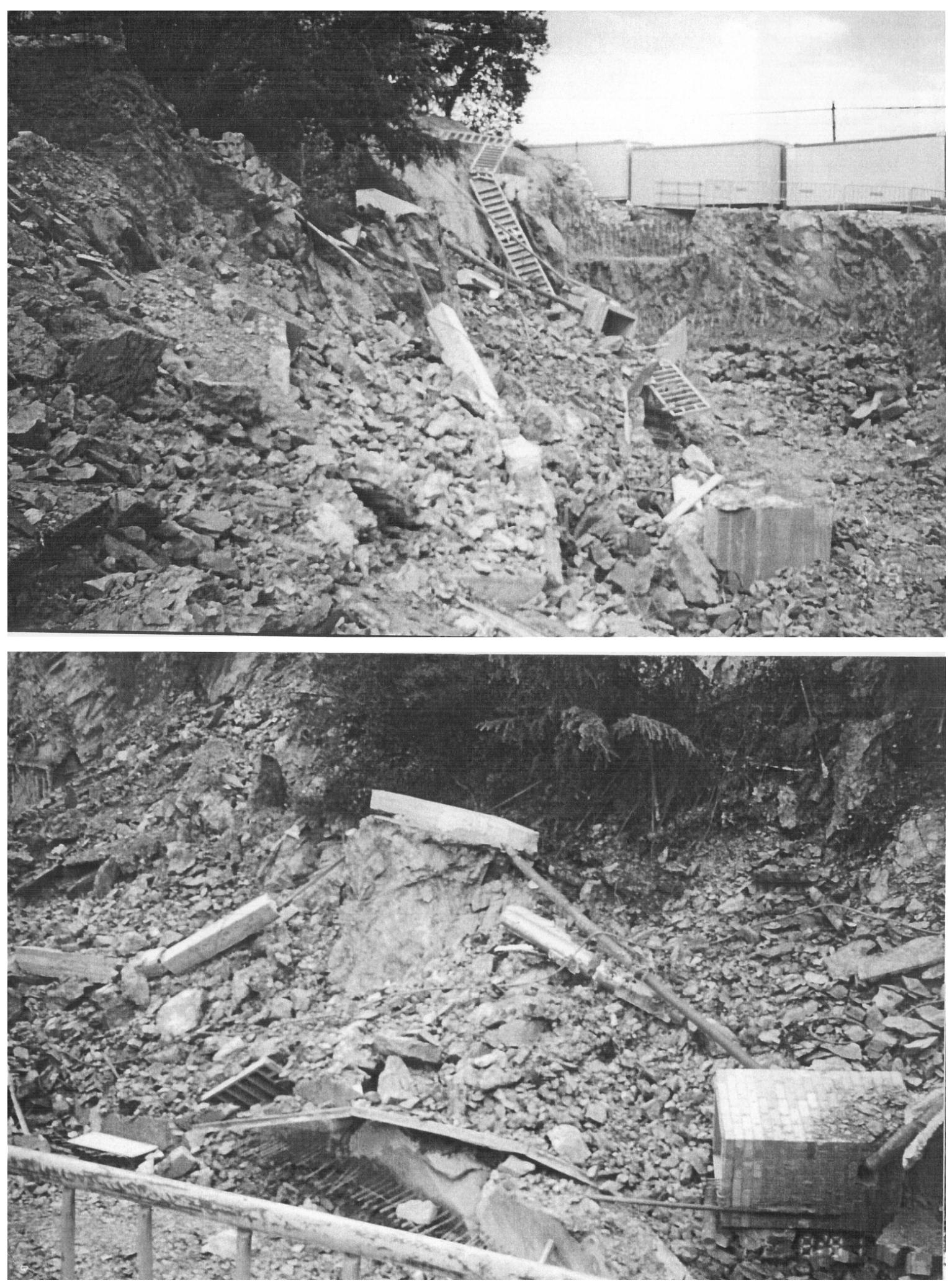

Figure 8. Detail of the failed wall. Parts of the broken piles and cap beam can be seen scattered on the ground surface. 

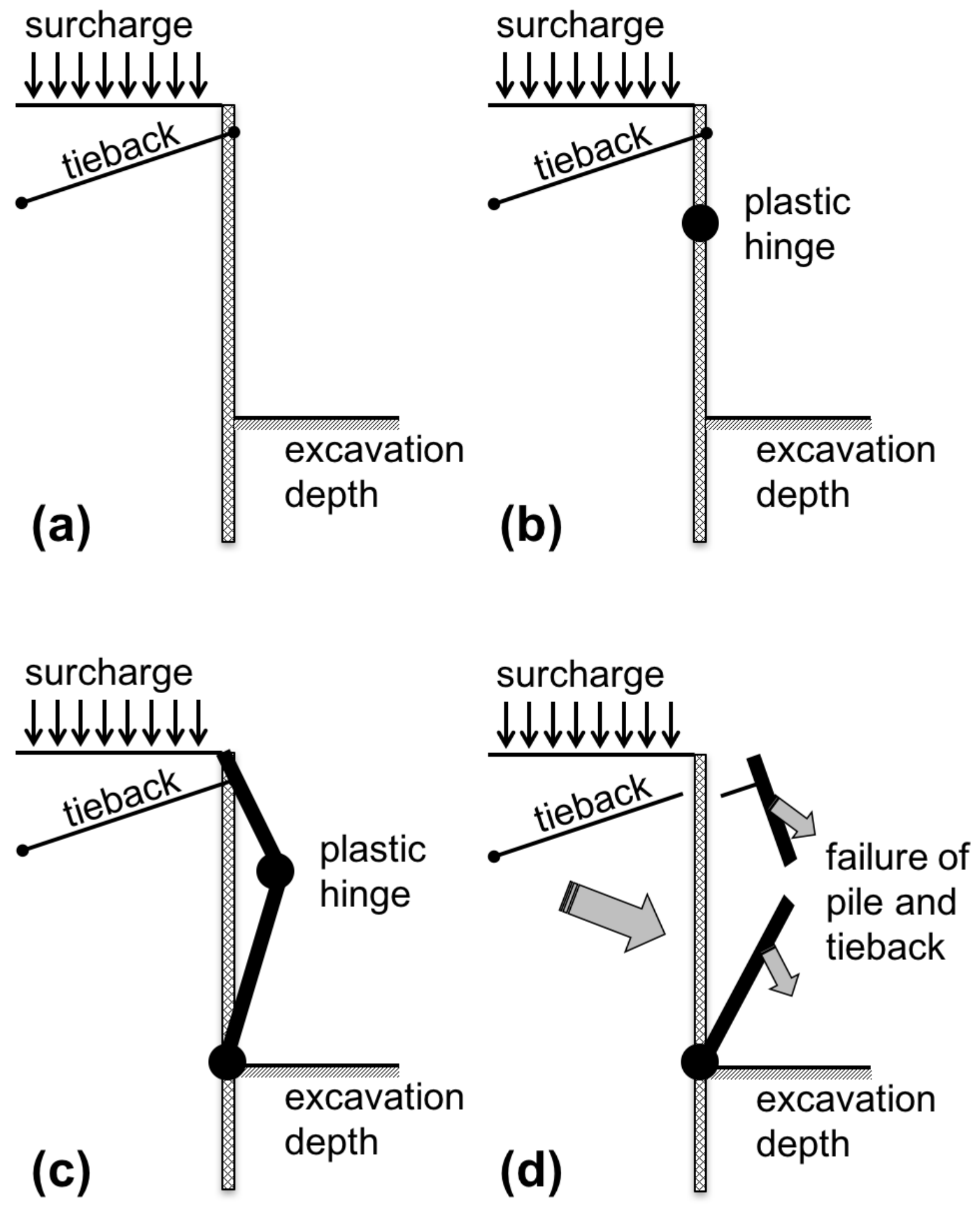

Figure 9. Collapse mechanism: (a) initial conditions; (b) a plastic hinge forms, arching occurs behind the wall and the ground cannot resist; (c) lateral deformation of the pile begins with the tieback within its strength limit; (d) large lateral deformation and failure of the tieback and pile. 


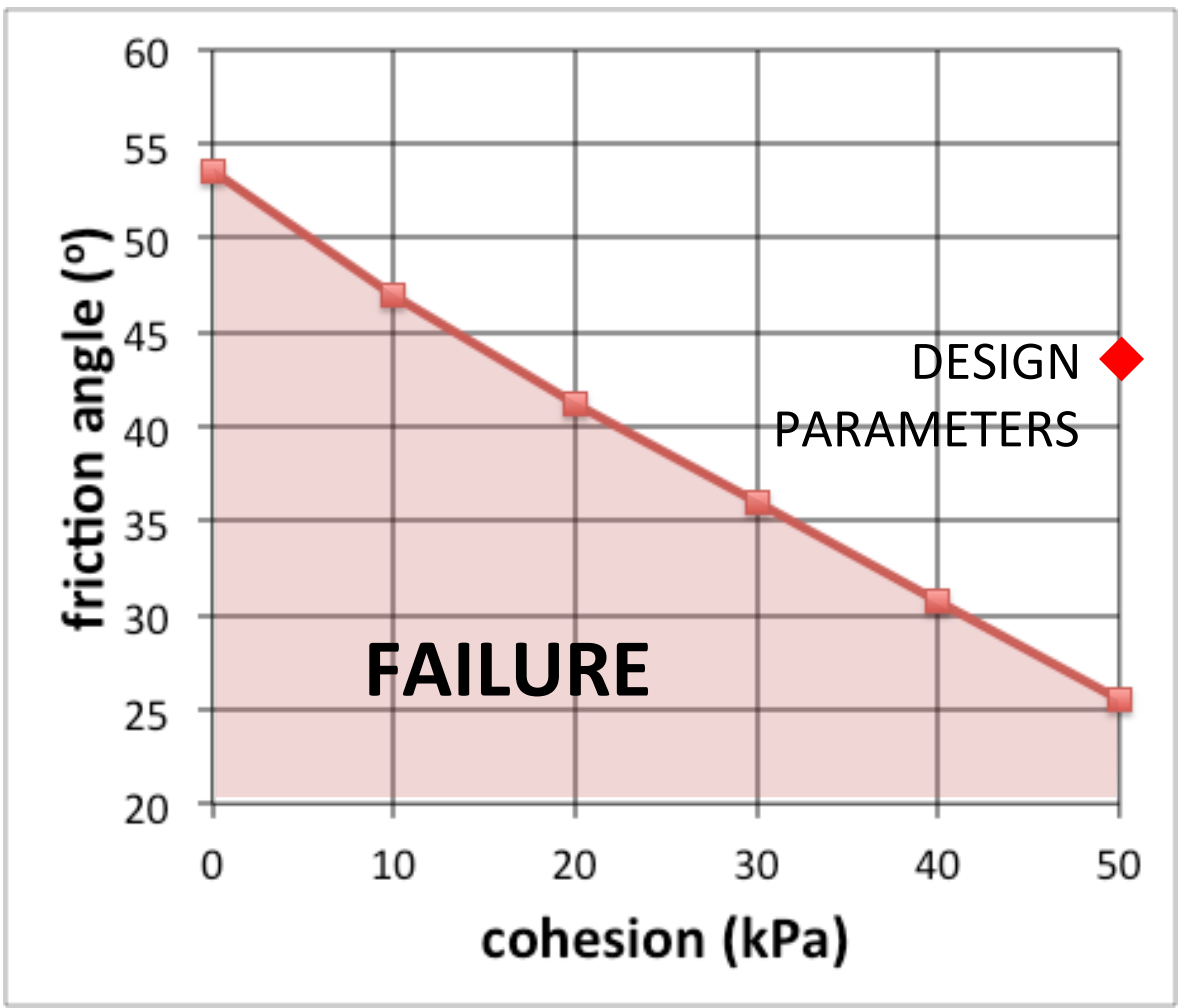

Figure 10. Limiting envelope of strength parameters combinations leading to failure. 


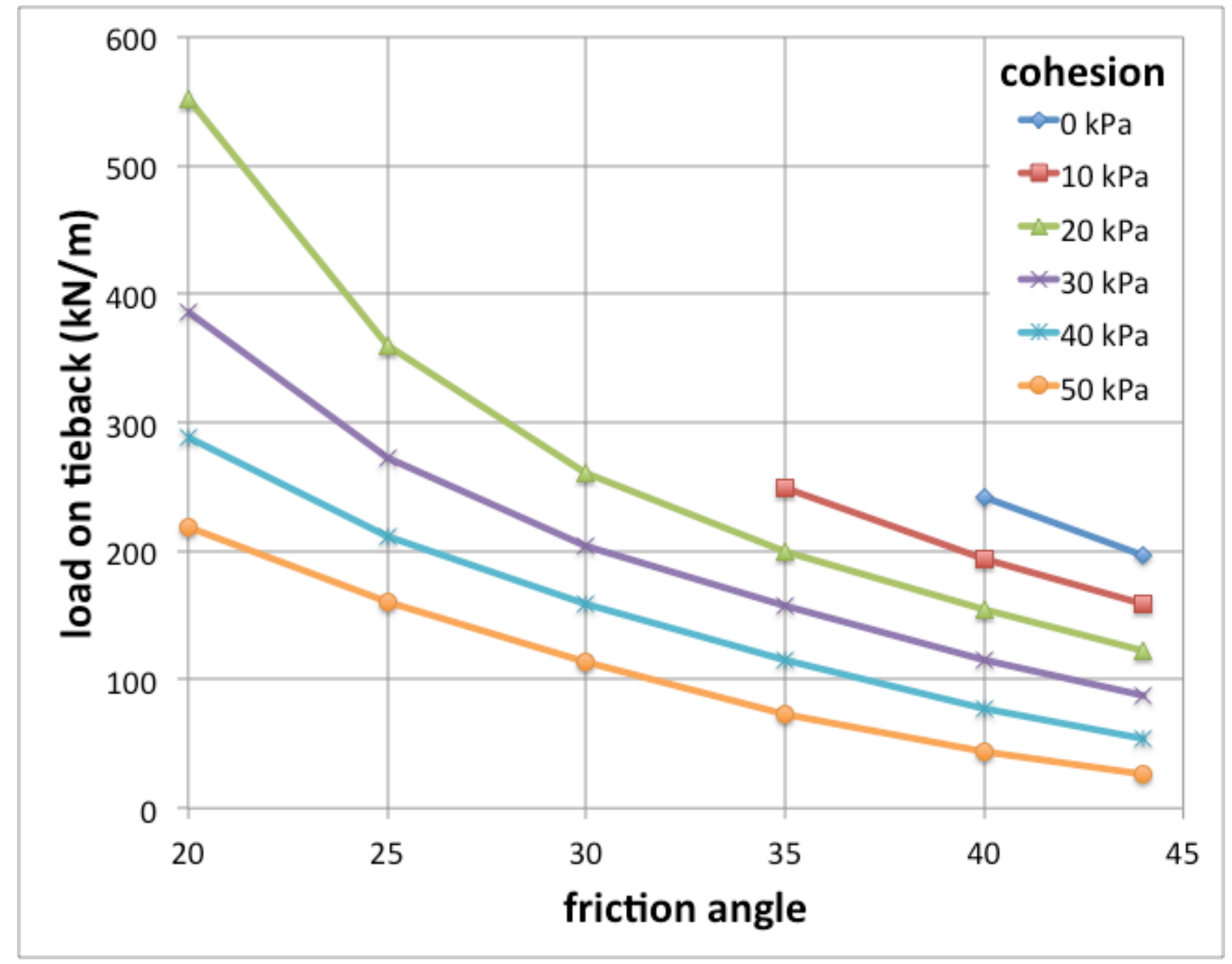

Figure 11. Predicted load on the upper tieback row at the end of construction for all strength parameters combinations analyzed. Missing points indicate failure before reaching this stage. 


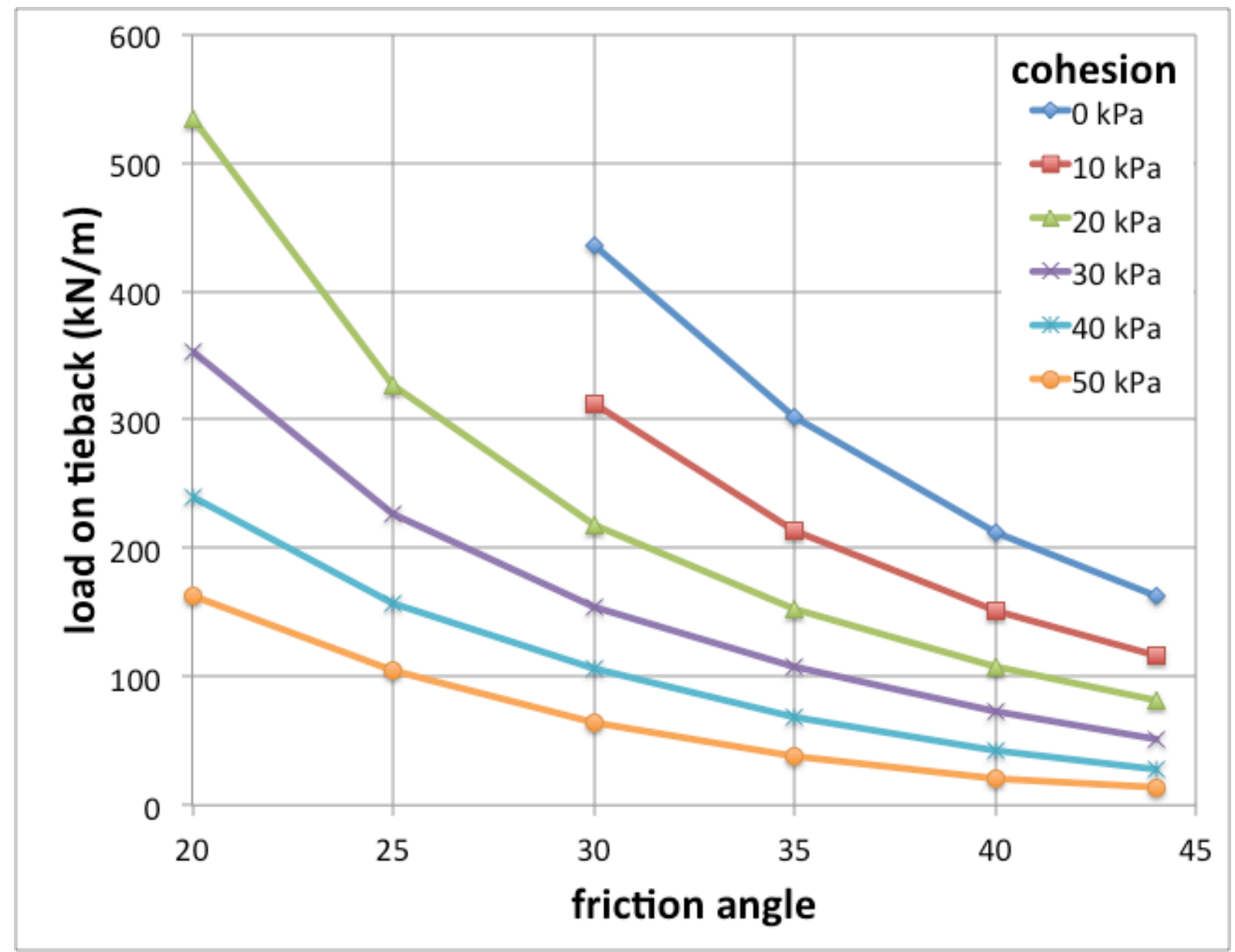

Figure 12. Predicted load on the upper tieback row at the end of construction stage 5 when the actual collapse occurred. Missing points indicate failure before reaching this stage. 


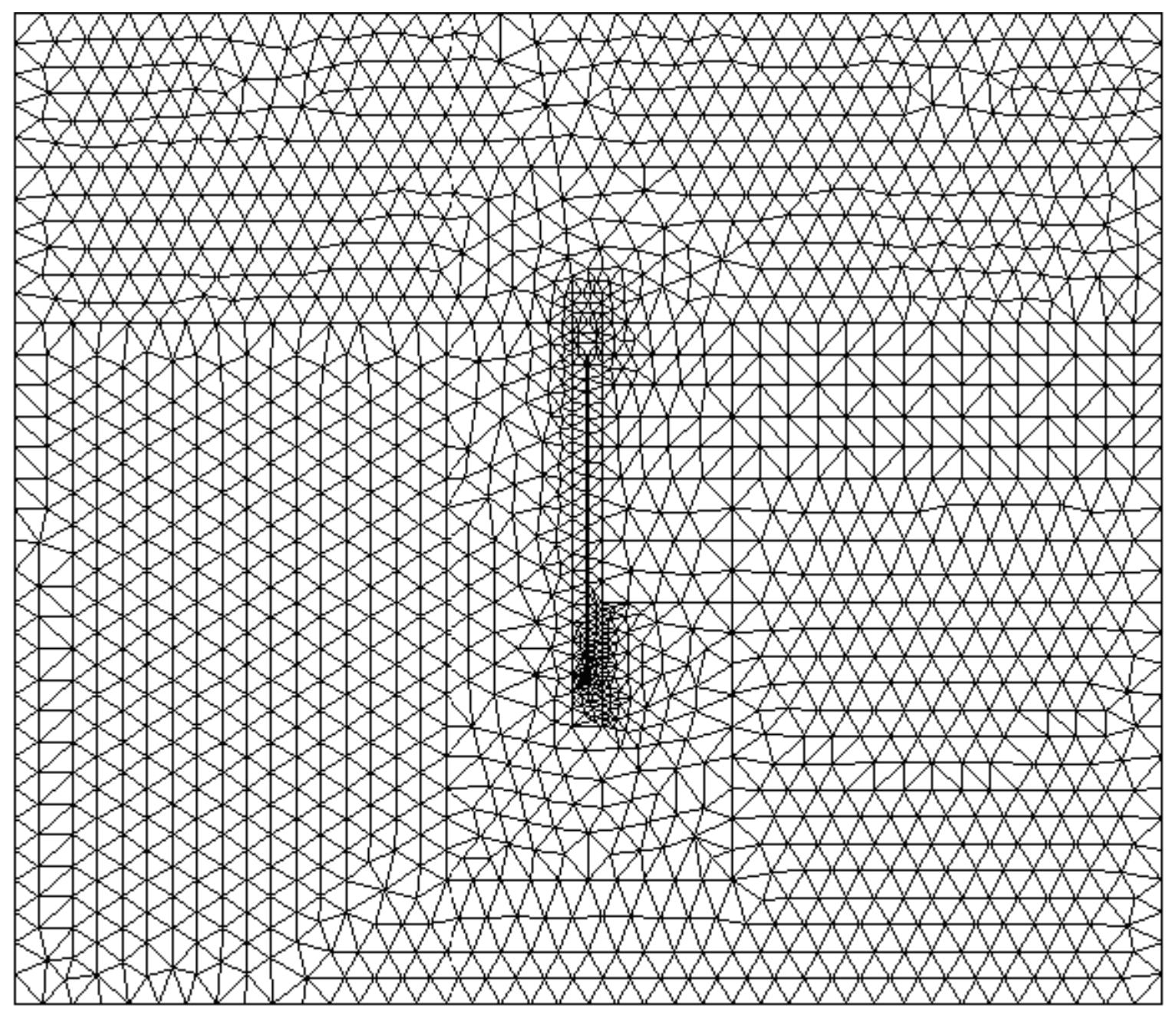

Figure 13. Initial (step 1) finite element mesh used with DRAC 

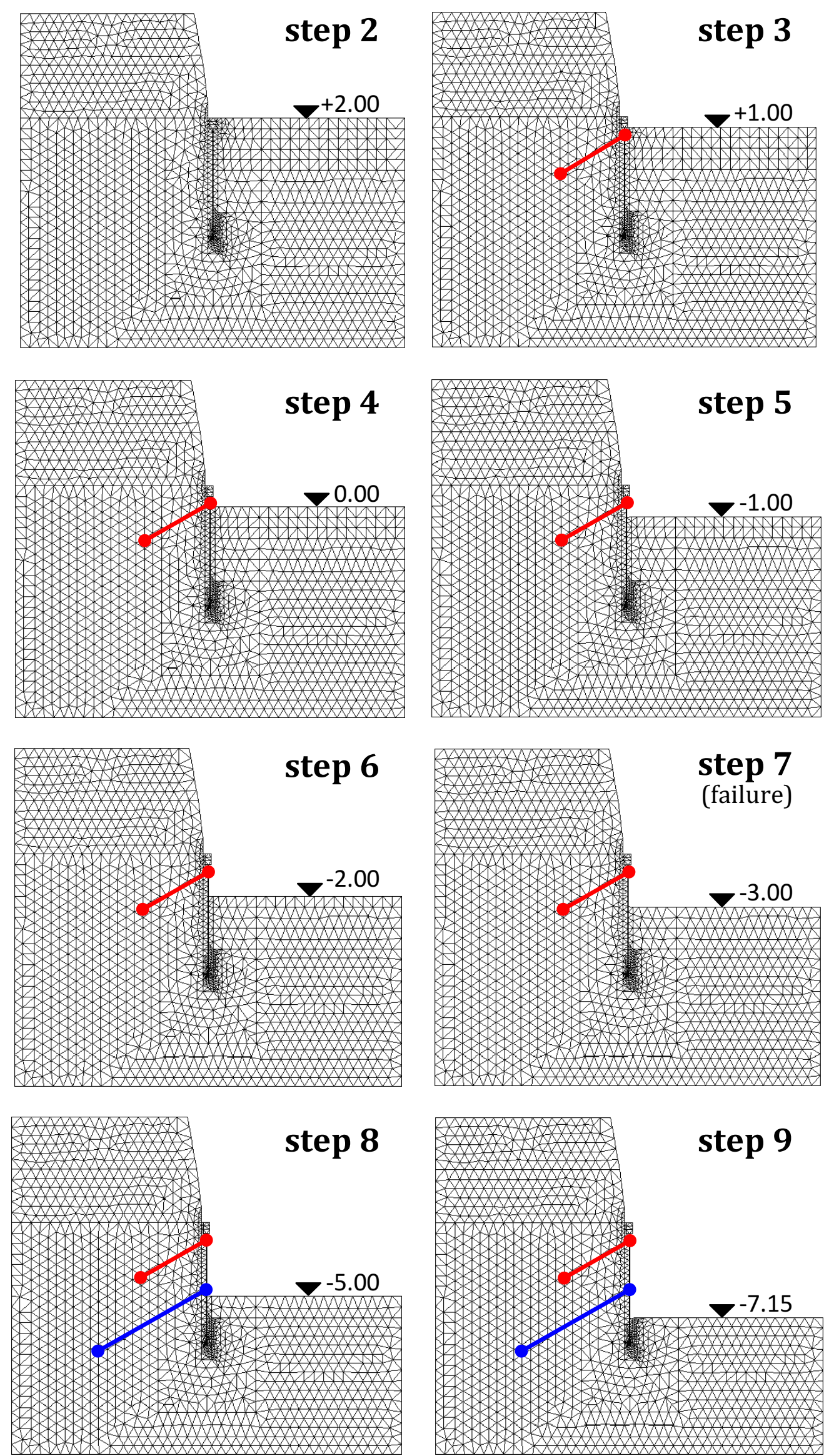

Figure 14. Excavation sequence with DRAC (step numbers refer to the numerical analysis, not to the construction sequence) 


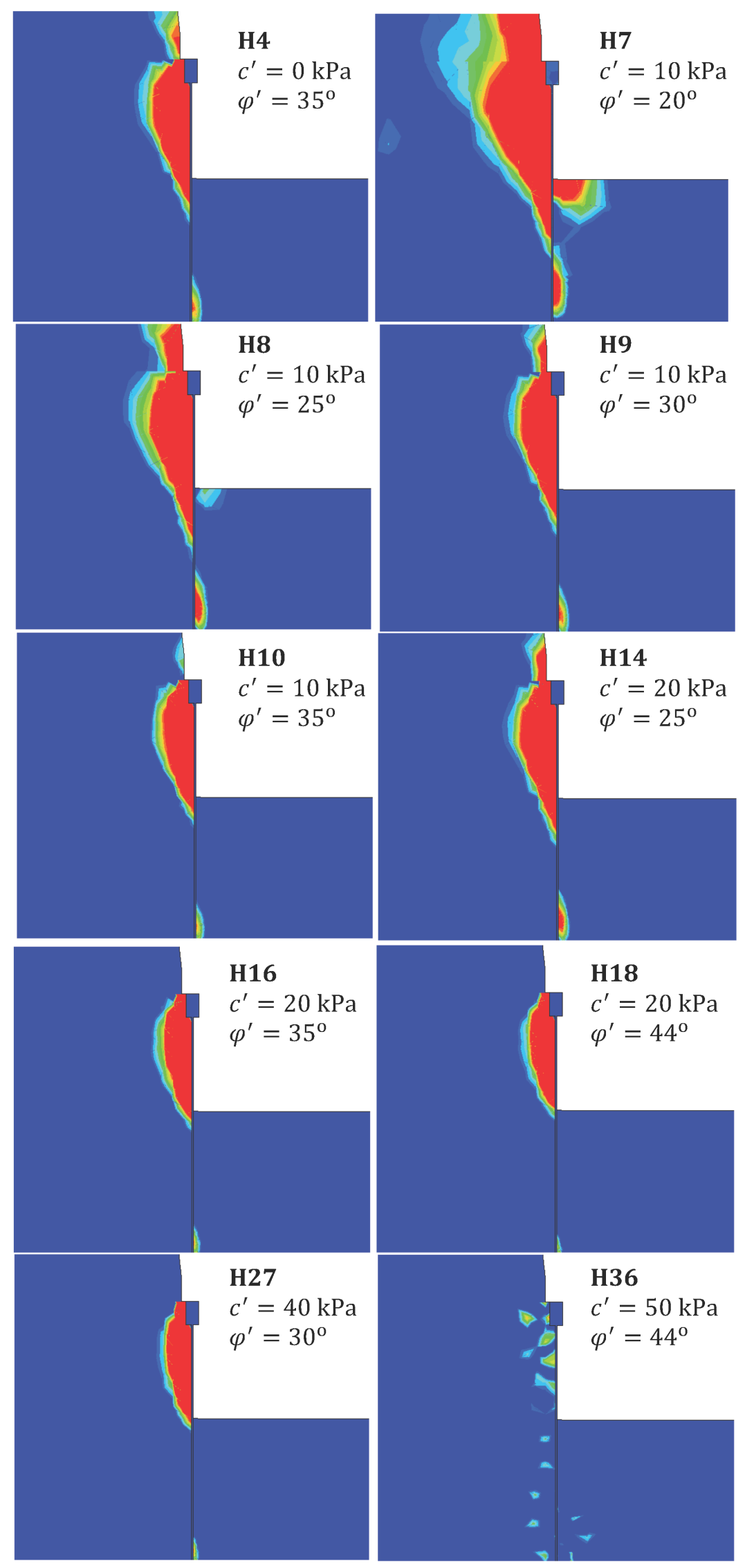

Figure 15. Extent of the plastic zone obtained with DRAC near the micropile wall after step 7 for the selected sets of strength parameters indicated 

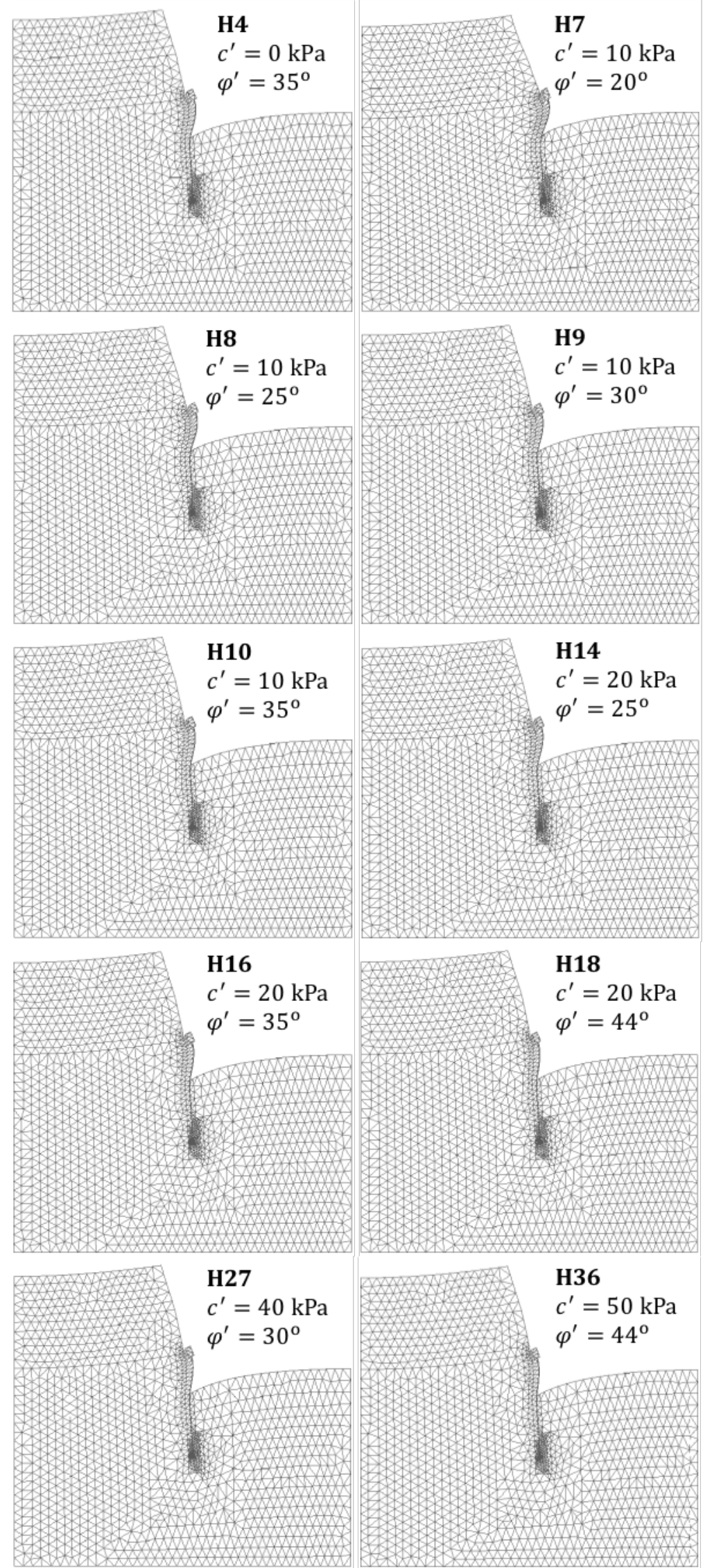

Figure 16. Deformed mesh obtained with DRAC near the micropile wall after step 7 for the selected sets of strength parameters indicated (magnification: $100 \times$ ) 